\title{
New RP-HPLC Method for Separation of Naja haje haje Venom and Studies of its Bactericidal Effect
}

\author{
Gâz Florea Șerban Andrei1*, Ciurca Diana¹, Mare Anca², Man Adrian², Cordoș Bogdan³, Grama Anda- \\ Lavinia ${ }^{1}$, Muntean Daniela-Lucia ${ }^{1}$ \\ ${ }^{1}$ Fundamental Pharmaceutical Science Department, Faculty of Pharmacy, University of Medicine and Pharmacy, Tîrgu Mureș, Romania \\ 2 Microbiology Department, Faculty of Medicine, University of Medicine and Pharmacy, Tîrgu Mureș, Romania \\ ${ }^{3}$ Medical Experimental Research Center, Faculty of Medicine, University of Medicine and Pharmacy, Tîrgu Mureș, Romania
}

\begin{abstract}
Background: Snake venom is a complex mixture of biologically active substances. Some peptides and proteins from snake have already demonstrated their therapeutically potential. The venom of Naja haje, an Elapidae member, has been analyzed from this point of view. Understanding the fully biochemical role of its enzymes has determined the scientists to find new separation and identification methods.

Objective: Our goal was to develop an optimal HPLC analytical method for separation and identification of Naja haje snake venom components, known for its neurotoxic activity. In addition, we wanted to find out if crude snake venom could inhibit the development of both Gram-positive and Gram-negative bacterial cultures. Materials and Method: Analysis of venom was performed on a HPLC system using a C16 column with UV detection at $210 \mathrm{~nm}$. The analysis was done using two mobile phases, containing different concentrations of acetonitrile and trifluoroacetic acid aqueous solution at different $\mathrm{pH}$ values. An elution gradient was set at a flow of $0.60 \mathrm{~mL} / \mathrm{min}$. Bactericidal activity was quantified by measuring inhibition diameter around an aseptically disk filled with crude venom using Staphylococcus aureus and Escherichia coli. Results: An optimal HPLC analytical method has been developed by changing different parameters such as the $\mathrm{pH}$ value of mobile phase A or the elution gradient. The best resolution were obtained at a pH value of 7.4 , in gradient varying from $5 \%$ to $45 \%$ in mobile phase B. Microbiological studies of the venom showed that Gram-positive bacteria growth was inhibited by crude venom, while on Gram-negative bacteria growth no effect was observed. Inhibition zone is dose-dependent and fresh crude venom is with $30 \%$ more potent than venom freeze and kept at $-55^{\circ} \mathrm{C}$. Conclusions: A comprehensive catalog of venom composition may serve as a starting point for studying structurefunction correlations of individual toxins for the development of new research tools and drugs of potential clinical use.
\end{abstract}

Keywords: snake venom, bactericidal studies, Staphylococcus aureus. Naja Haje, egyptian cobra

Received: 10 August 2015 / Accepted: 21 September 2015

\section{Introduction}

The production of toxic compounds by plants, animals and microorganism has fascinated humanity for millennia, in general for practical reasons. However, only recently toxinology - defined by Karmakar in "Forensic Medicine and Toxicology" as "the branch of toxicology which deals with the toxic substances produced by living organism (e.g. plant and animal venoms, poisons and toxins)" [1,2] - became a formalized discipline starting with 1962 when was founded "The International Society on Toxinology" [3]. Once the toxinology started to develop and pointed out how deadly toxins have been used to understand mechanism of normal homeostasis on both animals and humans [4], new drugs were designed and synthesized [5-7] based on snake venom enzymes activity such as neurotransmission, apoptosis or physiological signal transmission $[8,9]$.

Snake venoms are typically complex mixtures of mostly peptides, proteins, enzymes and other small substances with toxic and lethal properties that facilitate the immobilization, digestion of the prey as well as a defending method against predators. The life or death of these prey/predator encounters made the toxins to be fast-acting and potent molecule. For this reason, many toxins have attracted the

* Correspondence to: Șerban Andrei Gâz Florea

E-mail: andrei.gaz@umftgm.ro researchers' interest for using them as drug lead and/or as pharmacological tools [10].

In a sense, the field of snake venom proteomics has been under investigation since the very earliest biochemical studies on venoms where peptides and proteins were isolated and structurally and biologically characterized. The recent developments in analytical methods have led to exciting insights into the protein composition of venoms and subsequently their pathological activities.

Evolution of modern high throughput screening systems has helped scientist to recognize and extract new substances that show promising potential in the development of new anticancer agents [11-17].

Since snake venoms have a very high toxicity potential it has been suggested to use separated proteins as potential new therapeutic agents as defense against microbial diseases, especially on methicillin and vancomycin resistant Staphylococcus aureus (MRSA and VRSA) [18-22].

Proteomic analysis of the venoms of Naja species supports the hypothesis that snake venom proteomes contain a large number of enzymes. A comprehensive catalog of venom composition may serve as a beginning for studying structurefunction correlations of individual toxins for the development of new research tools and drugs of potential clinical use.

Keeping this in mind and since we intend to find new therapeutic uses for venom components a new optimal 
RP-HPLC with UV detection analytical method has been developed for separations of Naja haje haje snake venom proteins. We are also intend to test the antibacterial properties of Naha haje haje crude venom. Our aim was to find out if crude snake venom could inhibit the development of bacterial cultures.

\section{Materials and methods Venom source and storage}

Crude venom of Naja Haje Haje (Egyptian cobra) was milked "in-house" from an adult snake. The snake has been kept in captivity, in controlled conditions: it was warmed daily for 9 hours, using a $100 \mathrm{~W}$ lamp, it received water ad libitum and it was fed with mice once every 10-14 days. The keeping and feeding was in accordance with ethical rules of handling and keeping live animals in captivity. Any studies from this publication involving experimental research on animals is conform to the guiding principles of the Declaration of Helsinki.

The venom was used either immediately after milking, either freeze at $-55^{\circ} \mathrm{C}$ until further use.

\section{Chemicals and solvents}

All the chemicals and solvents used were of analytical grade from Merck (Germany) and were used without any further purification. All solutions were prepared with water purified by the NanoPure Diamond (Barnstead - Mili-Q Plus, Millipore SUA).

\section{Material for HPLC chromatography}

For the HPLC (Dionex - Ultimate 1100, USA) the reversed phase Acclaim C16, $5 \mu \mathrm{m}$, 4.6x250 mm (Dionex) with guard column was used. The elution was monitored at 210 $\mathrm{nm}$. The column was equilibrated with $95 \% \mathrm{H}_{2} \mathrm{O} / 0.1 \%$ TFA $/ 5 \%$ acetonitrile (solvent $\mathrm{A}$ ) and eluted with a flow rate of $0.6 \mathrm{~mL} / \mathrm{min}$ using $95 \%$ acetonitrile $/ 5 \%$ water $/ 0.1 \%$ TFA in a non-linear gradient, where $\mathrm{B}=10 \%$ at $\mathrm{t}=0 \mathrm{~min}, 10 \%$ at $\mathrm{t}=20 \mathrm{~min}, 25 \%$ at $\mathrm{t}=30 \mathrm{~min}, 45 \%$ at $\mathrm{t}=60 \mathrm{~min}, 45 \%$ at $\mathrm{t}=85 \mathrm{~min}, 65 \%$ at $\mathrm{t}=110 \mathrm{~min}$ and $10 \%$ at $\mathrm{t}=130 \mathrm{~min}$. The column was established at $40^{\circ} \mathrm{C}$, while the samples were cooled and kept at $6^{\circ} \mathrm{C}$. All the mobile phases were sonicate for 10 minutes before use. Data processing was performed with the aid of Chromeleon 7 software.

\section{Sample preparation}

The samples were prepared by diluting crude snake venom in solvent $A$ at a concentration of approximately $7-8 \mathrm{mg} /$ $\mathrm{mL}$. Samples were sonicated for 10 minutes, centrifuged for 5 minutes at $4000 \mathrm{G}$ and filtered through $0.45 \mu \mathrm{m}$ (Whatman, UK) discarding the first $5 \mathrm{~mL} .100 \mu \mathrm{L}$ of samples were injected in chromatographic system.

\section{Bacterial Stains}

Escherichia coli (ATCC 30040) and Staphylococcus aureus (ATCC 29213) used in this study were maintained in Tryptic Soy Broth (TSB) with glycerin media at $-70^{\circ} \mathrm{C} .24$ hours before the study, the strains were revitalized on Columbia blood agar.

Inoculum suspension of microbial cultures were prepared at 0.5 McFarland turbidity standard obtained in sterile saline solution, which is roughly equivalent to 150 million cells per $\mathrm{mL}\left(1.5 \times 10^{8} \mathrm{CFU} / \mathrm{mL}\right)$. Solution was homogeneously swabbed onto a Petri dishes containing agar medium. A bacterial lawn was formed on a Mueller-Hinton (Agar) plate, by spreading the suspension in three different direction. The plate was allowed to dry for 15 minutes and aseptically blank disks were placed on the medium surface. $5 \mu \mathrm{L}$ and $20 \mu \mathrm{L}$ fresh snake venom, as well as freeze venom were filled on the disks. Plates were allowed to stay at room temperature for 15 minutes in order to diffuse and getting a uniform distribution of the snake venom on the disks. Agar plates were incubated for 24 hours at $37^{\circ} \mathrm{C}$.

\section{Results}

In Elapid venoms, smaller-mass proteins (with or without enzymatic activity) are most abundant (e.g. three-finger toxins (3FTXs), phospholipase $\mathrm{A}_{2}\left(\mathrm{PLA}_{2}\right)$, nerve growth factor). Higher-mass enzymatic toxins are also present (e.g. phosphodiesterase, acetylcholinesterase, hyaluronidase) but in much more lower quantity. Figure 1 shows the RP-HPLC chromatograms obtained for the purification of Naja Haje Haje venom showing at about 33 minutes eluted peaks for neurotoxic proteins (3FTXs), at 35-36 minutes peaks of $\mathrm{PLA}_{2}$ enzymes, at 38-39 minutes peaks characteristics for toxins with hemolytic activity, and after 40 minutes are proteins with high molecular mass. In total 21 peaks were separated with a good resolution (the smallest resolution was 2.59) and good peak asymmetry (between 0.61 and 1.92).

Naja Haje Haje crude venom has also been tested for its antibacterial activity. On the basis of the observed results on disk diffusion (figure 2A), crude venom, either fresh or kept at $-55^{\circ} \mathrm{C}$, inhibited only the Gram-positive bacterial growth, exhibiting little or no effect on E. coli (figure $2 \mathrm{~B}$ ). The zone inhibition were measured and compared in figure 3 .

\section{Discussions}

A point of concern regarding the biological activity of different peptides and proteins from snake venom is the report that several of the medically and toxicologically effect can be different from slightly modified peptides and proteins. Correlated with the possible benefic effect of proteins present in the crude venom of Egyptian cobra encouraged us to develop an analytical method for separation as much protein as possible using reverse phase HPLC. Numerous previous publication reported separation of different peptides or proteins from crude snake venom [23-29]. Therefore, in this study we have reported the purification of Egyptian cobra venom as well as the antibacterial activity of crude venom.

We have noticed that mobile phase has an important role in the separation of different peptides and proteins. 


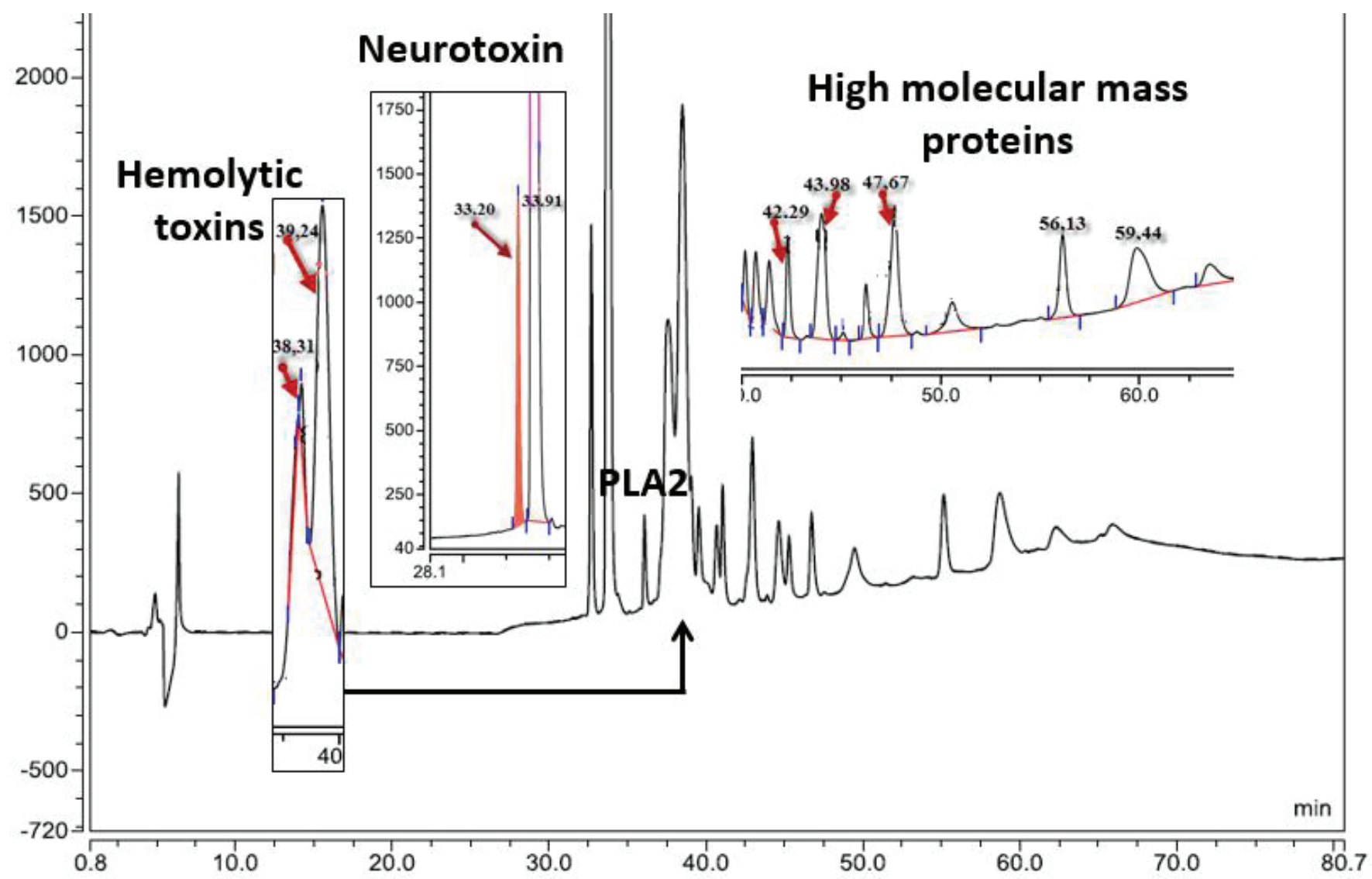

Fig. 1. Reverse phase HPLC separation of proteins from Naja Haje Haje crude snake venom (peak were assigned with data literature correlation)

For separation of the crude venom several mobile phase were tested. In addition, gradient was modified in order to achieve the best resolution between peaks and a good peak asymmetry. We have managed to separate distinctly 21 peaks with very good resolution (all the peaks are separated at the base).

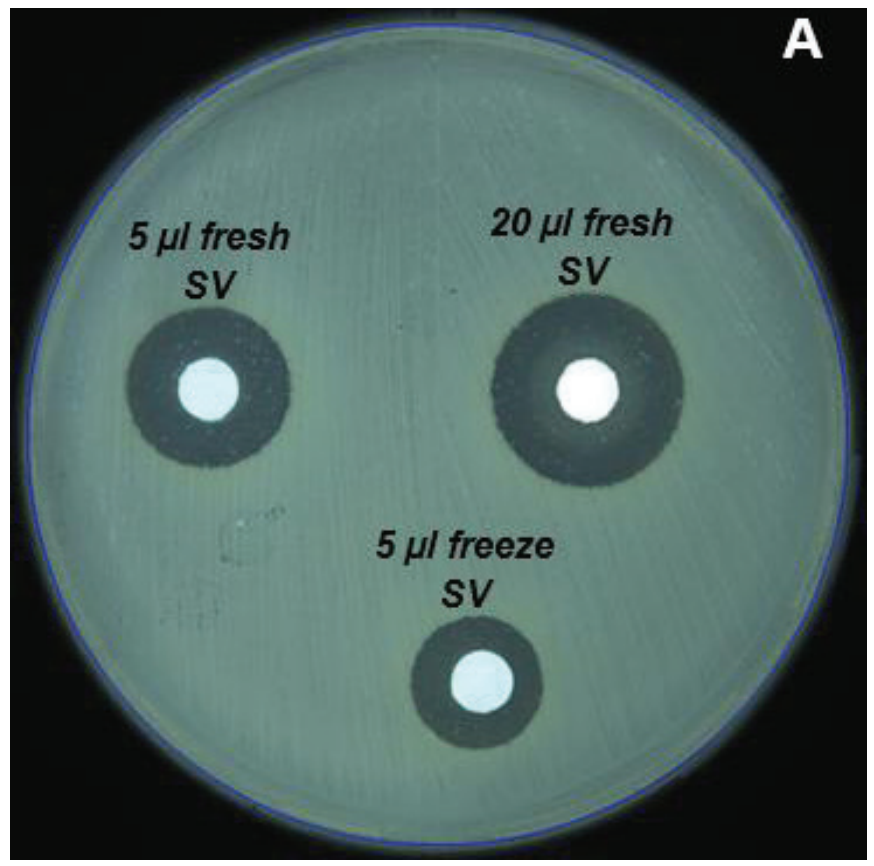

Furthermore, we intend to test the antimicrobial activity of the crude venom. Literature reported antimicrobial activities of snake venom [26,27,30-33], but from best of our knowledge there are no comparative studies between fresh collected venom and venom kept at low temperature. Crude fresh venom inhibit the growth of Gram-positive

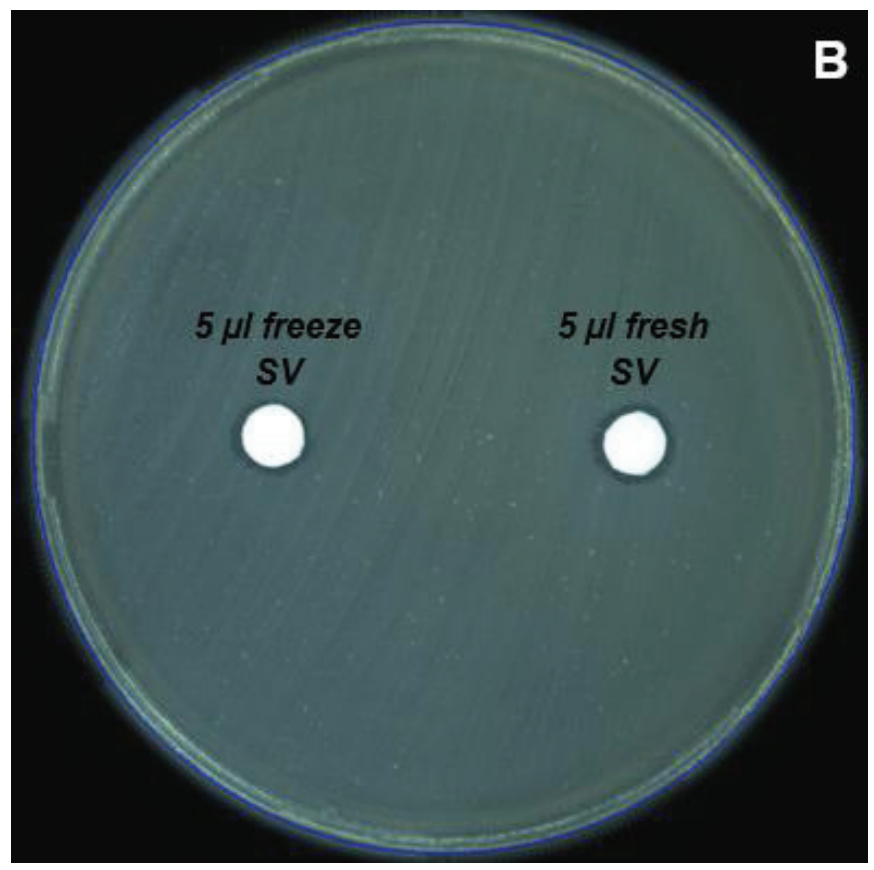

Fig. 2. Antimicrobial activity determined by adding fresh and freeze crude snake venom (SV) in a sterile disc (6 mm diameter) placed on Muller-Hinton agar plates containing a) Staphylococcus aureus and b) Escherichia. coli 


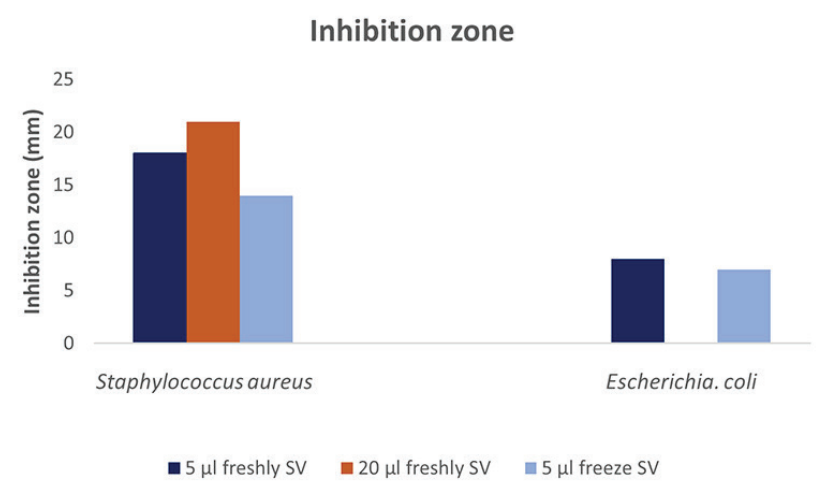

Fig. 3. Diameter zone comparison of crude venom on tested bacterial strains

bacteria, showing a dose-dependent manner (fig. 2). $5 \mu \mathrm{L}$ fresh venom showed an inhibition zone in average $18 \mathrm{~mm}$, while $20 \mu \mathrm{L}$ in the same conditions exhibited a diameter of inhibition of about $21 \mathrm{~mm}$. Using the same quantity of crude venom $(5 \mu \mathrm{L})$ we have compared the bacterial activity by measuring the inhibition zone for both fresh milked and freeze venom. It have been observed that crude venom once it has been cooled down and kept at low temperature it loses part of its biological activity exhibiting an inhibition zone reduced with more than $30 \%(14 \mathrm{~mm})$.

However, crude venom has no effect on Gram-negative E. coli most probably due to different bacterial cell wall. Fazeli and coworkers as well as $\mathrm{Li}$ and coworkers [34,35] showed that antibacterial activity of crude venom of scorpion and wasp is most probably due to cationic net charge proteins or peptides, which interact with anionic components of bacterial membranes resulting in irreversible damage to the cell.

In the future, a full screening of the Egyptian cobra venom is intended to be done. Purified fractions will be collected and characterized in order to establish the composition and the structure of peptides and proteins. Each fraction of Naja Hahe Haje venom will tested on a broad range of bacterial strains to determine which class of proteins is responsible for antibacterial activity. Tests will be extended on both Gram-positive and Gram-negative bacteria as well as on different types of Candida.

\section{Conclusions}

Given the structural complexity of the snake venom and seeing the huge potential of using its proteins in different therapies, development of new separation protocols is a necessity and an ongoing challenge for the researchers.

Our goal was to develop an optimal method for separating Naja Haje Haje venom proteins and testing antibacterial activity thereof.

In summary, the best chromatographic separation was achieved at a $\mathrm{pH}$ of mobile phase 7.4 , in gradient mode with detection at $210 \mathrm{~nm}$ being. We also noticed different bactericidal action between fresh and freeze crude venom as well as dose-dependent variability. Crude venom was in- hibited Staphyloccocus aureus grown, while on Escherichia Coli no effect was noticed.

Purified proteins from Egyptian cobra venom may represent a promising potential tool in the development of new drugs against resistant bacteria.

\section{Acknowledgments}

This paper was published under the frame of European Social Found, Human Resources Development Operational Programme 2007-2013, project no. POSDRU/159/1.5/S/136893

\section{Remarks}

First three authors share the same contribution on the experimental part.

\section{References}

1. Mebs D. Venomous and Poisonous Animals. A Handbook for Biologists, Toxicologists and Toxinologists, Physicians and Pharmacists. 1st Ed. Medpharm Scientific Publisher, Boca Raton: Stuttgart, Germany CRC Press. 2002:2.

2. Karmakar RN. Forensic Medicine and Toxicology, Oral, Practical \& M.C.Q. 3rd Edition. Academic Publishers, Published by Bimal Kumar Dhur, Kolkta, India. 2010:57

3. http://www.toxinology.org/

4. Birell GW, Earl S, Masci P. et al. Molecular diversity in venom from the Australian Brown snake, Pseudonaja textilis. Mol Cell Proteomics. 2006;5:379-389.

5. Calvete JJ, Juarez P, Sanz L. Snake venomics, strategy and applications. J Mass Spectrom. 2007;42:1405-1414.

6. Smith CG, Vane JR. The discovery of captopril. FASEB (Fed Am Soc Exp Biol) J. 2003;17:799-789.

7. Bryan J. From snake venom to ACE inhibitor. The discovery and rise of captopril. Pharm J. 2009;282:455-456.

8. Chippaux JP, Williams V, White J. Snake venom variability: methods of study, results and interpretation. Toxicon. 1991;29:1279-1303.

9. Bas M, Adams V, Suvorava T. Nonallergic angioedema; role of bradykinin. Allergy. 2007;62:842-856.

10. Craik DJ, Schroeder Cl. Peptides from Mamba Venom as Pain Killers. Angew Chem Int Ed. 2013;52:3071-3073.

11. Shanbhag VKL. Applications of snake venoms in treatment of cancer. Asian Pac J Trop Biomed. 2015;5(4):275-276.

12. Vyas VK, Brahmbhatt K, Bhatt H, Parmar U. Therapeutic potential of snake venom in cancer therapy: current perspectives. Asian Pac J Trop Biomed. 2013;3(2):156-162.

13. Finn R. Snake venom protein paralyzes cancer cells. J Natl Cancer Inst. 2001;93(4):261-262.

14. Al-Sadoon M, Rabah DM, Badr G. Enhanced anticancer efficacy of snake venom combined with silica nanoparticles in a murine model of human multiple myeloma: Molecular targets for cell cycle arrest and apoptosis induction. Cell Immunol. 2013;284:129-136.

15. El-Refael M, Sarkar N. Snake venom inhibits the growth of mouse mammary tumor cells in vitro and in vivo. Toxicon. 2009;54:33-41.

16. Das T, Bhattacharya S, Biswas A. Inhibition of leukemic U937 cell growth by induction of apoptosis, cell cycle arrest and suppression of VEGF, MMP-2 and MMP-9 activities by cytotoxin protein NN-32 purified from Indian spectacled cobra (Naja naja) venom. Toxicon. 2013;65:1-4.

17. Gordaliza M. Natural products as leads to anticancer drugs. Clin Trans Oncol. 2007;9:767-776.

18. Samy RP, Chow VTK et al. Antimicrobial Proteins from Snake Venoms: Direct Bacterial Damage and Activation of Innate Immunity against Staphylococcus aureus Skin Infection. Curr. Med. Chem. 2011;18(33):5104-5113.

19. Costa Torres AF, Dantas RT, Toyama MH et al. Antibacterial and antiparasitic effects of Bothrops marajoensis venom and its fractions: phosholipase A2 and L-amino acid oxidase. Toxicon, 2010;55:795-804.

20. Nair DG, Fry BG, Alewood P et al. Antimicrobial activity of omwaprin, a new member of the waprin family of snake venom proteins. J Biol Chem. 2007;402:93-104;

21. Fenard D, Lambeau G, Valentin E et al. Secreted phospholipases A(2), 
a new class of HIV inhibitors that block virus entry into host cells. J Clin Invest. 1999;104:611-618.

22. Samy RP, Thong TWJ et al. Antibacterial activity of snake, scorpion and bee venoms: a comparison with purified venom phospholipase A2 enzymes. J Appl Micriobiol. 2007;102:650-659.

23. Ständker $L$, Harvey $A L$, Béress $L$. et al. Improved method for the isolation, characterization and examination of neuromuscular and toxic properties of selected polypeptide fractions from the crude venom of the Taiwan cobra Naja naja atra. Toxicon 2012;60:623-631.

24. Zaqueo KD, Kayano AM, Stábeli RG et al. Isolation and biochemical characterization of a new thrombin-like serine protease from Bothrops pirajai snake venom. Biomed Res Int. 2014;2014:1-13.

25. Angulo Y, Castro A, Gutiérrez JM et al. Isolation and characterization of four medium-size disintegrins from the venom of Central American viperid snakes of the genera Antropoides, Bothrops, Cerrophidion and Crotalus. Biochemie 2014,107:376-384.

26. Hanane-Ziad-Meziane HF, Laraba-Djebari F. Purification, characterization and antibacterial activity of L-amino acid oxidase from Cerastes cereastes. J. Biochem. Mol. Toxic. 2014,28:347-354.

27. Nunes ES, Correia MTS et al. Purification of lectin with antibacterial activity from Bothrops leucurus snake venom. Comp. Biochem. Physiol., B: Comp. Biochem. 2011,159:57-63.

28. El Hakim AE, Abouelella AMK et al. Purification and characterization of a cytotoxic neurotoxin-like protein from Naja Haje haje venom that induces mitochondrial apoptosis pathway. Arch. Toxicol. 2011,85:941952.

29. Botes DP, Strydom DJ. A neurotoxin, toxin alpha, from Egyptian cobra (Naja Haje Haje) venom. I. Purification, properties, and complete amino acid sequence. J. Biol. Chem. 1969;244:4147-4157.

30. Wen YL, Wu BJ, Chang LS et al. Antibacterial and membrane-damaging activities of $\beta$-bungarotoxin B chain. J Pept Sci. 2012;19:1-8.

31. Chen LW, Kao PH, Fu YS, Hu WP, Chang LS. Bactericidal effect of Naja nigricollis toxin $\gamma$ is related to its membrane damaging activity. Peptides. 2011;32:1755-1763.

32. Samy RP, Al Qahtani et al. Sanke venom proteins: Development into Antimicrobial and Wound Healing Agents. Mini Rev Org Chem. 2014;11:4-14.

33. Al Ahmadi AJ, Mirakabbadi AZ et al. Investigation of the antibacterial effect of venom of the Iranian snake Echis carinatus. Iran J Vet Sci Technol (IJVST). 2010;2:93-100.

34. Jalaei J, Fazeli M, Rajaian H, Shekarforoush SS. In vitro antibacterial effect of wasp (Vespa orientalis) venom. J venom Anim Toxins Incl Trop Dis. 2014;20:1-6.

35. Zhao Z, Cao J, Li W et al. Imcroporin, a new cationic antimicrobial peptide from the venom of the scorpion Isometrus maculates. Antimicrob Agents Chemother. 2009;53(8):3472-3477. 